\title{
VIABILIDADE ECONÔMICA DA PRODUÇÃO DE LEITE EM SISTEMAS DE PRODUÇÃO SEMICONFINADO E CONFINADO NO OESTE DE SANTA CATARINA
}

\author{
Economic feasibility of milk production in semi-confined and confined \\ production systems in the West of Santa Catarina State
}

\begin{abstract}
Marco Antônio Marchesi Galeazzi ${ }^{1}$, Daniela dos Santos de Oliveira ${ }^{2}$, Amito José Teixeira ${ }^{3}$, Gilberto Pereira ${ }^{4}$, Tiago João Pereira de Lima ${ }^{5}$, Carla Pasinato ${ }^{6}$
\end{abstract}

\footnotetext{
${ }^{1}$ Engenheiro Agrônomo - Curso de Pós-Graduação em Especialização em Nutrição de Animais de Produção.

${ }^{2}$ Orientadora - Coordenadora Curso de Pós-Graduação em Especialização em Nutrição de Animais de Produção, Coordenadora do Curso de Medicina Veterinária da URI Erechim.E-mail: danielaoliveira@, uricer.edu.br

${ }^{3}$ Zootecnista, Coordenador do Curso de Agronomia da URI Erechim.

${ }^{4}$ Professor, Matemático, Coordenador do Setor de Pós-Graduação e Extensão da URI Erechim

${ }^{5}$ Engenheiro Agrônomo- Prefeitura de Santo Expedido/RS

${ }^{6}$ Engenheira Agrônoma.
}

Data do recebimento: 23/09/2020 - Data do aceite: 18/06/2021

RESUMO: A produção de leite é considerada uma das principais atividades agropecuárias praticadas no Brasil, porém enfrenta mensalmente a oscilação de mercado e de preços do produto, estando os produtores sempre em busca de melhores preços e lucratividade para permanecerem na atividade. Levando em conta o máximo ganho dentro da propriedade, torna-se importante avaliar a forma de produção e o custo operacional da fazenda nas tomadas de decisão. O objetivo do presente trabalho foi avaliar as diferenças e oscilações de preços do ano de 2019 nos sistemas de produção confinado e semiconfinado. O estudo foi realizado a partir de visitas a seis propriedades localizadas no Oeste do Estado de Santa Catarina, através da coleta de dados econômicos e zootécnicos para mensuração da lucratividade. Na pesquisa observou-se 
que, do total de produtores o preço pago por litro de leite foi superior para os produtores em sistema de confinamento e estes produtores obtiveram média anual superior à obtida pelo preço líquido do índice CEPEA Brasil. Constatou-se que o volume de produção e número de animais em ordenha foi maior para os produtores no sistema em confinamento e que obtiveram uma margem operacional efetiva média de $\mathrm{R} \$ 307,41$ vaca mês $^{-1}$ contra $\mathrm{R} \$ 157,32$ vaca mês ${ }^{-1}$ no semiconfinamento. A análise de custo operacional efetivo se mostrou um indicador de relevância para a gestão das fazendas.

Palavras-chave: Bovinocultura de leite. Sistema de produção. Custo. Margem.

\begin{abstract}
Milk production is considered one of the main agricultural activities in Brazil, but it faces monthly market and product prices fluctuation. Due to this, producers have to be always looking for better prices and profitability to remain in the activity. Taking into account the maximum gain of the property, it is important to evaluate the form of production and the farm operating cost in decision-makings. The aim of this work was to evaluate the differences and price fluctuations in the year 2019 in cattle in confined and semi-confined production systems. The study was carried out from visits to six properties located in the west of Santa Catarina state, through the collection of economic and zootechnical data to measure profitability. It was observed that out of the total number of producers, the price paid per liter of milk was higher for producers who used the confinement system, and these producers obtained an annual average higher than that obtained by the net price of the CEPEA Brasil index. It was found that the production volume and number of animals in milking was higher for producers using the confinement system and that obtained an average profitability of $\mathrm{R} \$ 307.41$ cow month ${ }^{-1}$, against $\mathrm{R} \$$ 157.32 cow month ${ }^{-1}$ in semi-confinement. The analysis of effective operating cost proved to be a farm management relevant indicator.
\end{abstract}

Keywords: Dairy Cattle Farming. Production system. Cost. Margin

\section{Introdução}

A cadeia produtiva do leite tem se constituído numa das mais complexas e representativas do agronegócio brasileiro. Conforme dados da EMBRAPA (2019), o Brasil é considerado, na atualidade, o terceiro maior produtor mundial de leite, tendo encerrado o ano de 2018 com uma produção de 33,4 bilhões de litros produzidos. A região sul do país tem forte representatividade no cenário nacional da produção de leite, com 11,9 bilhões de litros produzidos, sendo destes, Santa Catarina responsável por 2,98 bilhões, em que o oeste catarinense contribui por $77 \%$ desta produção.

Os empreendimentos rurais passaram por diferentes mudanças recentes, tanto gerenciais, quanto produtivas e que, de acordo com Martins et al. (2014), as transformações 
aconteceram, principalmente, pela incorporação de novas tecnologias para aumento da competitividade e redução nos custos de produção, de forma a tornar o empreendimento rural mais lucrativo e eficiente. Para Barbosa e Souza (2014), sistemas de produção com animais confinados é uma evolução que permite maior produtividade por área e, consequentemente, maior remuneração do capital investido.

No estado de Santa Catarina, vem crescendo o número de produtores adotando sistemas de confinamento para vacas leiteiras com uso de dietas totais, seja no modelo Free-Stall ou Compost Barn. Entretanto, devido ao perfil das propriedades rurais da região, ainda é grande o número de produtores que trabalham com sistemas a pasto, somados a uma suplementação volumosa e concentrados. Conforme cita Barbosa e Souza (2014), isso pode estar relacionado ao menor custo dos modelos com base no pastejo em relação ao confinamento. Outro fator a ser levado em consideração é descrito por Jung e Matte Jr. (2017), onde citam que na Região Sul do Brasil, destaca-se o sistema de produção familiar, sendo a produção de leite a atividade âncora na composição da renda dos pequenos agricultores, impactando no desenvolvimento regional.

Analisando os preços pagos aos produtores, Viana et al. (2010) apontam que, até o final da década de 1980, o estado atuava mediante regulação dos preços finais e pagos ao produtor. Com a abertura econômica dos anos 90, o mercado passou a condicionar a dinâmica agrícola. Houve ainda a entrada do Mercosul, o aumento da renda dos consumidores, elevação da demanda final de leite, atratividade do setor para grandes investimentos, a necessidade de redução de custos e a melhoria de qualidade através das instruções normativas da atividade.

Além do preço pago pela matéria-prima, um indicador importante a ser analisado pelas propriedades leiteiras são os custos operacionais efetivos (COE) que implicam desembolso pelo produtor e que são exigidos para que as operações produtivas ocorram, sendo, portanto, imprescindíveis (BARBOSA; SOUZA, 2014).

A alimentação dos animais nos sistemas de produção de leite tem grande influência sobre a lucratividade das empresas rurais. Entre os fatores que influenciam a eficiência de produção, o custo com a alimentação do rebanho é a mais importante variável dos custos operacionais de produção, e os alimentos concentrados representam de 30 a $40 \%$ destes custos (RENNÓ et al., 2008).

De acordo com Ferrazza et al. (2015), a comparação entre os indicadores obtidos em diferentes sistemas de produção, considerando fatores que sejam comuns entre os sistemas, possibilita um embasamento na elaboração do planejamento, estabelecimento de metas, avaliação dos resultados e a tomada de decisões estratégicas dentro das propriedades rurais.

Objetivou-se com este estudo avaliar, durante o ano de 2019, o preço pago ao produtor nos sistemas de produção de leite confinado e semiconfinado, no oeste de Santa Catarina, comparando aos custos operacionais de produção em cada sistema e a Margem Operacional Efetiva (MOE).

\section{Material e Métodos}

O trabalho foi conduzido em propriedades leiteiras localizadas no oeste do estado de Santa Catarina. As propriedades rurais analisadas possuem mão-de-obra familiar e sistemas de produção de leite em confinamento, onde a alimentação era baseada em silagem, feno e ração, caracterizados como Produtor 1, 2 e 3, sendo participantes de um programa de assistência técnica e gerencial. Os Produtores 4, 5 e 6 possuíam manejo com 
base em pastejo rotacionado, somado a uma suplementação diária de silagem e ração.

Os dados foram coletados de janeiro a dezembro de 2019, através de visitas mensais in loco às propriedades e planilhamento dos dados econômicos e zootécnicos.

Adotou-se para elaboração da planilha de acompanhamento mensal a metodologia desenvolvida por Camargo e Novo (2009), descrevendo as receitas, investimentos e todos os custos conforme a sua categoria, usando o Software Excel ${ }^{\circledR}$.

Foram avaliados, neste trabalho, os indicadores de custo operacional efetivo (COE - R\$ Litro $^{-1}$ ), volume de leite produzido (Litros mês ${ }^{-1}$ ), valor pago ao produtor ( $\mathrm{R} \$$ Litro $\left.^{-1}\right)$, número de vacas em lactação $\left(\mathrm{N}^{\mathrm{o}}\right.$ Vacas mês ${ }^{-1}$ ) e margem operacional efetiva (MOE - R\$ vaca mês ${ }^{-1}$ ).

Conforme descreve Matsunaga et al. (1976) o custo operacional é dividido em Custo Operacional Efetivo (COE) e Custo Operacional Total (COT). O COE é composto pelos itens do custo variável e a parcela dos custos fixos que representam saída de caixa e representam a capacidade de a propriedade arcar com os seus custos desembolsáveis. $\mathrm{O}$ COT é composto pelo COE, o custo com a mão de obra familiar e a parcela de custos não desembolsáveis, como é o caso da depreciação, e representa a capacidade de a empresa arcar com seus custos, remunerar a mão de obra familiar e ainda fazer reposição de seus ativos (GARCIA et al., 2020). Para Castro Junior et al. (2015) o COE é composto pelos itens de custo considerados variáveis, representados pelas despesas em dinheiro, em mão-de-obra, sementes, fertilizantes, energia, combustíveis, manutenções, água, alimentos, medicamentos preventivos e curativos, assistência técnica, juros, impostos e taxas, entre outros.

Para a completa comparação de preços, foi realizado um levantamento, durante o ano de 2019, junto ao Centro de Estudos Avançados em Economia Aplicada (CEPEA), do Departamento de Economia, Administração e Sociologia da ESALQ, que possui como metodologia gerar valores ao leite cru integral refrigerado (leite de vaca), negociado entre produtores e indústria/cooperativa de laticínios, em Reais por litro ( $\left.\mathrm{R} \$ \mathrm{~L}^{-1}\right)$.

De acordo com a metodologia descrita, a média "Brasil" é obtida pela ponderação dos preços médios estaduais de BA, GO, MG, $\mathrm{SP}, \mathrm{PR}, \mathrm{SC}$ e RS, conforme suas respectivas participações na porcentagem do volume amostrado (CEPEA, 2019). Além disto, a média Brasil é informada em preços líquidos, que representam os valores "recebidos" pelos produtores sem contabilizar frete e impostos, e preços brutos, que incluem os custos de frete e impostos.

\section{Resultados e Discussão}

As médias mensais calculadas durante a execução do trabalho, nas seis propriedades analisadas na região oeste de Santa Catarina, estão apresentados na Tabela I, que descreve os valores médios entre janeiro e dezembro de 2019, para indicadores de preço do CEPEA bruto e líquido e preço do litro de leite pago ao produtor.

Ao analisar o preço por litro de leite pago aos produtores, verificou-se que em comparação ao valor médio bruto do CEPEA Brasil, nenhum dos produtores obteve média igual ou superior à Média Bruta e Líquida CEPEA $\left(1,5096 \mathrm{R} \$ \mathrm{~L}^{-1}\right)$, podendo estar relacionado com os valores de acordo com a qualidade do produto entregue.

Entretanto, quando se comparou ao preço bruto médio de $1,4707 \mathrm{R} \$ \mathrm{~L}^{-1}$ por litro, para o estado de Santa Catarina, no indicador CEPEA, no período de janeiro a dezembro de 2019, verificou-se que o Produtor 3 obteve média anual superior. Isso pode ser 
VIABILIDADE ECONÔMICA DA PRODUÇÃO DE LEITE EM SISTEMAS DE PRODUÇÃO SEMICONFINADO E CONFINADO NO OESTE DE SANTA CATARINA

Tabela I - Indicadores de preço do CEPEA, relação entre preço bruto e preço líquido nos sistemas de Confinamento e Semiconfinamento na região Oeste de Santa Catarina/2019

\begin{tabular}{|c|c|c|c|c|c|c|}
\hline \multirow{2}{*}{$\begin{array}{c}\text { Média } 12 \text { meses } \\
\qquad R \$ L^{-1}\end{array}$} & \multicolumn{3}{|c|}{ Confinamento } & \multicolumn{3}{|c|}{ Semiconfinamento } \\
\hline & $\begin{array}{c}\text { Produtor } \\
1\end{array}$ & $\begin{array}{c}\text { Produtor } \\
2\end{array}$ & $\begin{array}{c}\text { Produtor } \\
\mathbf{3}\end{array}$ & $\begin{array}{c}\text { Produtor } \\
4\end{array}$ & $\begin{array}{c}\text { Produtor } \\
5\end{array}$ & $\begin{array}{c}\text { Produtor } \\
6\end{array}$ \\
\hline Preço Bruto CEPEA & 1.5096 & 1.5096 & 1.5096 & 1.5096 & 1.5096 & 1.5096 \\
\hline Preço Líquido CEPEA & 1.4088 & 1.4088 & 1.4088 & 1.4088 & 1.4088 & 1.4088 \\
\hline Preço leite ao produtor & 1.4327 & 1.4326 & 1.4777 & 1.4631 & 1.2633 & 1.3035 \\
\hline
\end{tabular}

atribuído ao custo de frete no estado de Santa Catarina ser inferior à média Brasil devido à proximidade entre indústrias de laticínios e produtores. Outra hipótese é descrita por Azevedo e Politi (2008), em que a grande participação do leite longa vida, no mercado de leite fluido, afeta os preços recebidos pelos produtores de leite.

Quando comparado aos valores de preço líquido, o cenário é favorável aos produtores do sistema de confinamento, que obtiveram média anual superior ao valor de R $\$ 1,4088$ $\mathrm{R} \$ \mathrm{~L}^{-1}$, apontado pelo índice CEPEA. Além destes, o produtor 4 , em sistema de semiconfinamento, que alcançou a média de preço anual de 1,4631 R $\$ \mathrm{~L}^{-1}$, também ficou acima do índice. Os maiores preços obtidos por estes produtores podem estar relacionados ao maior volume de produção mensal, conforme apresentados na Tabela III.

Ainda conforme dados do CEPEA (2020), o ano de 2019 pode ser dividido em dois momentos bem distintos: o primeiro semestre, onde o produtor estava num cenário de recuperação de margens, com altas no valor recebido pelo litro de leite. Já, o segundo semestre, foi marcado pela retração no fluxo de caixa das propriedades, uma vez que a receita foi prejudicada pela queda no preço do leite e os custos aumentaram com a alta do preço da ração.
Atualmente, muitos laticínios adotaram para a composição de preços pagos ao produtor, sistemas de bonificação conforme volume e os resultados das análises de qualidade pelos laboratórios da Rede Brasileira de Qualidade do Leite. Essa mudança na forma de pagamento visa a estimular os produtores a melhorar continuamente a qualidade do leite, conforme os padrões estipulados pelas Instruções Normativas 76 e 77 (BRASIL, 2018). Assim, as variações de preços pagos aos seis produtores analisados, conforme a Tabela I, podem estar relacionadas às diferenças nos teores de sólidos do leite, nos resultados de contagem bactéria total, contagem de células somáticas e volume produzido.

A Tabela II demonstra os valores médios, entre janeiro e dezembro de 2019, para indicadores do preço do leite pago ao produtor, custo operacional efetivo e porcentagem de comprometimento do $\mathrm{COE}$ em relação ao preço pago por litro de leite para produtores do oeste de Santa Catarina, nos sistemas de confinamento e semiconfinamento.

Conforme Oliveira et al. (2007), o conhecimento do custo operacional efetivo e suas implicações a curto prazo, é fundamental para a gestão e viabilidade da atividade leiteira. Ao se avaliar o custo operacional efetivo (COE) nos dois modelos de produção, conforme a Tabela II, pode-se observar que o Produtor 6 
(sistema de semiconfinamento) obteve maior custo para produção, chegando a uma média de $\mathrm{R} \$ 1,1663$ para cada litro produzido no período analisado. Ao contrário do que se imaginava anteriormente à pesquisa, os produtores que apresentaram o menor custo operacional efetivo foram aqueles pertencentes ao modelo de confinamento, o que pode ser atribuído à hipótese de o volume de produção diluir os custos.

Ainda, conforme a Tabela II, pode-se observar que a porcentagem do COE em relação ao preço recebido pela matéria-prima, comprometeu entre 65 e $90 \%$ do valor recebido. Telles et al. (2017), em estudo realizado no Rio Grande do Sul, obtiveram um custo geral de produção de 59\%. Lopes \& Santos (2012), realizando um comparativo econômico entre propriedades leiteiras em sistema de semiconfinamento e confinamento em Minas Gerais, encontraram um custo operacional efetivo, em relação à receita da produção de Leite, de $82,6 \%$ para o sistema de semiconfinamento e $95,4 \%$ para o confinamento.

Em trabalho realizado por Assis et al. (2017), considerando o custo operacional efetivo, sendo apenas os desembolsos mensais para produção, observaram que a alimentação e a mão de obra são os itens que possuem maior representatividade, pois analisando este custo entre os anos de $2002 \mathrm{e}$ 2011, somente estes dois itens representaram $72,1 \%$ do COE.
A alimentação tem grande papel dentro do COE nas propriedades analisadas, principalmente pelo uso de rações e silagens, que apresentam um valor por quilograma de matéria seca maior quando comparadas ao pasto. Em outro trabalho realizado por Reis et al. (2001), onde foram analisados os custos da atividade leiteira no sul de Minas Gerais, foi observada uma participação de $45,83 \%$ da alimentação no custo da atividade.

Além da alimentação e da mão de obra, o COE irá variar conforme o grau de investimento despendido por cada propriedade, gastos com medicamentos para sanidade dos rebanhos, impostos, gastos com assistência técnica, adubos, sementes, manutenções e demais despesas que geram desembolsos mensais aos produtores. Ao estudar a rentabilidade de sistemas de produção de leite, no município de Nazareno em Minas Gerais, Lopes et al. (2011) obtiveram uma média das despesas com alimentação, para 4 propriedade analisadas, no período de 12 meses, de $51,6 \%$ do COE. No mesmo trabalho, os pesquisadores encontraram despesas de 20,01\% do COE em mão de obra, 3,76\% do COE em sanidade e $6,74 \%$ do COE em energia.

Em um estudo desenvolvido entre março de 2008 e fevereiro de 2009, no estado de Minas Gerais, em três sistemas de produção, foi observado, pelos autores, que os itens do $\mathrm{COE}$ que exerceram maior impacto foram a

Tabela II - Relação de indicadores percentuais do Custo Operacional e preço pago ao produtor por litro de leite nos sistemas confinamento e semiconfinamento no Oeste de Santa Catarina/2019

\begin{tabular}{|c|c|c|c|c|c|c|}
\hline \multirow[b]{2}{*}{ Média 12 meses } & \multicolumn{3}{|c|}{ Confinamento } & \multicolumn{3}{|c|}{ Semiconfinamento } \\
\hline & $\begin{array}{c}\text { Produtor } \\
1\end{array}$ & $\begin{array}{c}\text { Produtor } \\
2\end{array}$ & $\begin{array}{c}\text { Produtor } \\
\mathbf{3}\end{array}$ & $\begin{array}{c}\text { Produtor } \\
4\end{array}$ & $\begin{array}{c}\text { Produtor } \\
5\end{array}$ & $\begin{array}{c}\text { Produtor } \\
6\end{array}$ \\
\hline Preço leite $\mathbf{R} \$ \mathbf{L}^{-1}$ & 1.4327 & 1.4326 & 1.4777 & 1.4631 & 1.2633 & 1.3035 \\
\hline COE RS $\mathrm{L}^{-1}$ & 1.0575 & 0.9615 & 0.9696 & 1.0201 & 0.9843 & 1.1663 \\
\hline MOE R\$ L $\mathbf{L}^{-1}$ & 0,3752 & 0,4711 & 0,5081 & 0,4430 & 0,2790 & 0,1372 \\
\hline COE \% & 73.8 & 67.1 & 65.6 & 69.7 & 77.9 & 89.5 \\
\hline
\end{tabular}


alimentação, com 53,57\% do COE, mão-de-obra $(15,89 \%)$; sanidade $(5,22 \%)$ e energia (4,21\%) (SANTOS; LOPES, 2014).

É importante frisar que o custo operacional efetivo na atividade leiteira nunca será o mesmo para cada propriedade, independente do sistema adotado, pois este custo será diluído conforme o aumento na produção $\mathrm{e}$ consequente aumento de receita, com a venda de animais e com os subprodutos gerados. Além disso, é de fundamental importância que sejam analisados os custos totais de produção para a correta tomada de decisão na atividade.

Entre janeiro e dezembro de 2019 foi gerado o indicador de número vacas em lactação, conforme a Tabela III, onde se pode observar que os produtores, no sistema de produção confinado, apresentaram média anual no número de vacas em ordenha ao mês maior que os do sistema em semiconfinamento. Para o sistema confinado as médias foram $45,44,7$ e 32,5 para os produtores 1,2 e 3, respectivamente, contra médias de 29,3 , 17,3 e 17,8 para os produtores do sistema semiconfinado.

Uma das alternativas para a intensificação da produção de leite são os modelos de galpões com cama em compostagem que, de acordo com Brito (2016), consiste em uma instalação para vacas leiteiras de alta produção, com o objetivo de proporcionar conforto e bem-estar animal, proporcionando melhorias nos índices produtivos e sanitários com a possibilidade de redução dos custos de produção. Este sistema está cada vez mais se difundindo entre os produtores de leite no estado de Santa Catarina, principalmente pelo aumento de lotação animal nas fazendas e facilidade para execução de manejos.

Corroborando com o exposto, Radavelli (2018), em sua dissertação sobre caracterização do sistema de compost barn, em regiões subtropicais brasileiras, cita áreas de cama disponíveis de 6 a $16 \mathrm{~m}^{2}$ por animal. Em contrapartida, trabalhando com pastagens do gênero coast-cros, Córdova (2012) cita taxas de lotação de 5,8 a 7,3 UA ha-1. Portanto, para os produtores optarem por um sistema confinado ou semiconfinado, um dos fatores que se deve levar em consideração é a disponibilidade de área.

Considerando a produção mensal em litros por vaca, os sistemas de confinamento proporcionaram maiores médias ao longo do ano de 2019, sendo a maior média entre os produtores do estudo de $776,16 \mathrm{~L}_{\text {vaca }}$ mês $^{-1}$, conforme mostra a Tabela III. Esse resultado pode estar relacionado à genética dos rebanhos, aspectos nutricionais, disponibilidade de alimento e água, conforto térmico, menor gasto energético e sanidade.

Para Brito (2016) ao implantar o sistema de Compost Barn em duas fazendas leiteiras, no estado de Minas Gerais, foi observado um aumento de $36 \%$ na média diária, passando

Tabela III - Indicadores de volume de leite e Margem Operacional Efetiva ao mês/animal, no Oeste de Santa Catarina, nos sistemas de confinamento e semiconfinamento/2019

\begin{tabular}{|c|c|c|c|c|c|c|}
\hline \multirow[b]{2}{*}{ Média 12 meses } & \multicolumn{3}{|c|}{ Confinamento } & \multicolumn{3}{|c|}{ Semiconfinamento } \\
\hline & $\begin{array}{c}\text { Produtor } \\
1\end{array}$ & $\begin{array}{c}\text { Produtor } \\
2\end{array}$ & $\begin{array}{c}\text { Produtor } \\
\mathbf{3}\end{array}$ & $\begin{array}{c}\text { Produtor } \\
4\end{array}$ & $\begin{array}{c}\text { Produtor } \\
5\end{array}$ & $\begin{array}{c}\text { Produtor } \\
6\end{array}$ \\
\hline Volume (Litro Mês' ${ }^{-1}$ ) & 34927 & 26541 & 22462 & 15663 & 9760 & 10082 \\
\hline $\mathrm{N}^{0}$ vacas lactação Mês ${ }^{-1}$ & 45 & 44.7 & 32.5 & 29.3 & 17.3 & 17.8 \\
\hline Média (L vaca mês ${ }^{-1}$ ) & 776.16 & 594.2 & 691.13 & 533.97 & 565.78 & 565.36 \\
\hline MOE (R\$ vaca mês $\left.{ }^{-1}\right)$ & 291.22 & 279.88 & 351.14 & 236.54 & 157.89 & 77.54 \\
\hline
\end{tabular}


de 21,4 L vaca dia ${ }^{-1}$ para 29,1 L vaca dia $^{-1}$, na fazenda $1 \mathrm{e}$, aumento de $19 \%$, na fazenda 2, passando de 25,1 para $29,9 \mathrm{~L}_{\text {vaca }} \mathrm{dia}^{-1}$, após 12 meses de alojamento no sistema de Compost Barn Corroborando, Garda (2016) cita o alto custo de sistemas em confinamento, não sendo compensatório para vacas de menor produção.

A MOE obtida através da análise dos dados, nos dois sistemas de produção, diferem entre si, mas confirmam a hipótese de que quanto maior a produção, maior a diluição dos custos. Este indicador de eficiência econômica evidencia que a atividade leiteira tem condições de sobreviver no curto e médio prazo, pois todos os produtores, no presente estudo, obtiveram, ao longo do período avaliado, resultados positivos, sendo que a média de MOE para o sistema de confinamento foi de $\mathrm{R} \$ 307,41$ vaca mês $^{-1}$ contra R\$ 157,32 vaca mês $^{-1}$ no semiconfinamento.

O resultado de MOE, menos expressivo, foi obtido pelo produtor 6 , em sistema de semiconfinamento (pasto com suplementação), que fechou o período de 12 meses com lucro médio de 77,54 R\$ vaca mês ${ }^{-1}$, conforme Tabela III. Este produtor está em processo de descapitalização, tendo condições de produzir apenas em curto prazo. Ao persistir tal situação, é possível que, a longo prazo, o pecuarista venha a ficar inviabilizado na atividade leiteira e precise optar por outra exploração ou forma de aplicação do capital.

Ainda, segundo Bueno (2004), o aumento da produção animal, implica acréscimo dos custos de produção, levando à redução das margens de lucro, tornando-se inviável economicamente para produtores em pequena escala. É importante ressaltar que somente a MOE não permite definir qual o melhor sistema de produção, pois seria necessária uma análise profunda dos custos totais de produção e das características de cada propriedade.

\section{Conclusão}

Os preços brutos médios, indicados pelo CEPEA Brasil, foram superiores aos obtidos na prática durante o estudo em Santa Catarina, o que indica que se deve analisar os preços de forma regionalizada, levando em consideração o indicador de preço líquido.

Considerando-se os indicadores econômicos estimados nesta pesquisa, pode-se concluir que os COEs representam um custo elevado para a atividade leiteira, sendo este um indicador de relevância para a gestão das fazendas.

Sistemas de produção em confinamento tendem a obter maiores médias de produção por animal, diluindo os custos operacionais e proporcionando melhor MOE.

\section{REFERÊNCIAS}

ASSIS, L. P. de; VILLELA, S. D. J.; LOPES, M. A.; SANTOS, R. A. dos; RESENDE, E. S.; SILVESTRE, L. H. A.; SILVA, H. B. S.; MARTINS, P. G. M. A. Análise econômica e de custos de produção da atividade leiteira durante 10 anos em uma propriedade do Alto Vale do Jequitinhonha. Custos e @gronegócio online, n. 2, v. 13, p. 176-200, 2017. Disponível em: http://repositorio.ufla. br/handle/1/32307. Acesso em: 26 jul. 2020.

AZEVEDO, P. F. de; POLITI, R. B. Concorrência e estratégias de precificação no sistema agroindustrial do leite. Revista de Economia e Sociologia Rural, n. 3, v. 46, p. 767-802, 
VIABILIDADE ECONÔMICA DA PRODUÇÃO DE LEITE EM SISTEMAS DE PRODUÇÃO SEMICONFINADO E CONFINADO NO OESTE DE SANTA CATARINA

jul./set. 2008. Disponível em: https://www.scielo.br/scielo.php?script=sci_arttext\&pid =S0103-20032008000300008. Acesso em: 02 ago. 2020 .

BARBOSA, F. A.; SOUZA, R. C. Administração financeira do sistema de produção da bovinocultura de leite. In: SILVA, J. C. P. M. da; VELOSO, C. M.; FRANCO, M. de O.; OLIVEIRA, A. S. de. Manejo e administração em bovinocultura leiteira. 2. ed. Viçosa/MG: 2014, p.521-560.

BRASIL. Ministério da Agricultura, Pecuária e Abastecimento. Instrução Normativa No 76, de 26 de novembro de 2018. Diário Oficial da União, Brasília, 2018. Disponível em: http://www.in.gov. br/materia/-/asset_publisher/Kujrw0TZC2Mb/content/id/52750137/do1-2018-11-30-instrucaonormativa-n-76-de-26-de-novembro-de-2018-52749894IN\%2076. Acesso em: 08 dez. 2019.

BRITO, E. C. Produção intensiva de leite em compost barn: Uma avaliação técnica e econômica sobre a sua viabilidade. 2016. 57 f. Dissertação (Mestrado em Ciência e Tecnologia do Leite e Derivados) - Universidade Federal de Juiz de Fora, Juiz de Fora, MG, 2016.

BUENO, P. R. B.; RORATO, P. R. N.; DÜRR, J. W.; KRUG, E. E. B. Valor econômico para componentes do leite no estado do Rio Grande do Sul. Revista Brasileira de Zootecnia, n. 6, v. 33, p. 2256-2265, 2004. Disponível em: https://www.scielo.br/scielo.php?script=sci_arttext\&pid=S151635982004000900011\&lang=pt. Acesso em: 25 jul. 2020.

CAMARGO, A. C. de; NOVO, A. L. M. Manual da planilha de avaliação da propriedade leiteira. EMBRAPA - Pecuária Sudeste, jun. 2009. Disponível em: http://www.cooperideal.com.br/ arquivos/MPAP.pdf. Acesso em: 22 jan. 2019.

CASTRO JUNIOR, L. G.; ANDRADE, F. T.; OLIVEIRA, D. H. Fruticultura. In: Campo futuro: resultados 2015. Brasília: CNA, p.57-75, 2015.

CEPEA. Metodologia. Centro de estudos avançados em economia aplicada, ESALQ/USP, jan. 2019. Disponível em: https://www.cepea.esalq.usp.br/upload/kceditor/files/Cepea_Leite_ MetodologiaCompleta_jan_19.pdf. Acesso em: 25 jul. 2020.

CEPEA. Boletim do Leite. Centro de estudos avançados em economia aplicada, ESALQ/ USP, ano 26, n. 295, 2020. Disponível em: https://www.cepea.esalq.usp.br/upload/revista/ pdf/0376668001579201456.pdf. Acesso em: 25 jul. 2020.

CÓRDOVA, U. de A. (org.). Produção de leite à base de pasto em Santa Catarina. Florianópolis: Epagri, 2012.

EMBRAPA - EMPRESA BRASILEIRA DE PESQUISA AGROPECUÁRIA. Anuário Leite 2019. Disponível em: http://ainfo.cnptia.embrapa.br/digital/bitstream/item/198698/1/Anuario-LEITE-2019. pdf. Acesso em: 08 dez. 2019.

FERRZA, R. de A.; LOPES, M. A.; BRUHN, F. R. P.; MORAES, F. de. Índices de desempenho zootécnico e econômico de sistemas de produção de leite com diferentes tipos de mão de obra. Ciência Animal Brasileira, n. 02, v. 16, p. 193-204, abr./jun. 2015. Disponível em: http://www.scielo.br/scielo. php?pid=S1809-68912015000200193\&script=sci_abstract\&tlng=pt. Acesso em: 07 dez. 2019.

GARCIA, F.Z.; CARVALHO, C.A.B. DE; PERES, A.A. DE C.; SANTOS, D.A.; MENDONÇA, F.M. DE; MALAFAIA, P.; FERREIRA, R.L. Analysis of economic and financial performance indexes of cow-calf systems. Custos e @gronegócio on line, v. 16, n. 1, 2020.Disponível em: www. custoseagronegocioonline.com.br. Acesso em: 23de junho de 2021.

GARDA, N. Sistema de Produção: produção de leite pelo sistema de Compost Barn. UPF Campus Casca, Casca, RS, 2016. Disponível em: http://repositorio.upf.br/bitstream/riupf/1075/1/ CAS2016NATALIA\%20GARDA.pdf. Acesso em: 25 jul. 2020.

JUNG, C. F.; MATTE JR., A. A. M. Produção leiteira no Brasil e características da bovinocultura leiteira no Rio Grande do Sul. Ágora, n. 01, v. 19, p. 34-47, 2017. Disponível em: https://online. 
unisc.br/seer/index.php/agora/article/view/8446. Acesso em: 07 dez. 2019.

LOPES, M. A.; SANTOS, G dos. Comparativo econômico entre propriedades leiteiras em sistema intensivo de produção: um estudo multicascos. Revista Brasileira de Saúde e Produção Animal, n. 3, v. 13, p. 591-603, 2012. Disponível em: https://www.scielo.br/scielo.php?pid=S151999402012000300001\&script=sci_abstract\&tlng=pt. Acesso em: 25 jul. 2020.

LOPES, M. A.; SANTOS, G. dos; RESENDE, M. C.; CARVALHO, F. M.; CARDOSO, M. G. Estudo da rentabilidade de sistemas de produção de leite no Município de nazareno, MG. Ciência Animal Brasileira, n. 1, v. 12, p. 58-69, 2011. Disponível em: https://www.revistas.ufg.br/vet/ article/view/7725/8768. Acesso em: 25 jul. 2020.

MARTINS, H. C.; MUYLDER, C. F. de; LOPES, C. A.; LA FALCE, J. Os impactos da difusão tecnológica na bovinocultura leiteira: um estudo dos integrantes da cadeia agroindustrial do leite em um município de Minas Gerais. Ciência Rural, n. 6, v.44, p. 1141-1146, 2014. Disponível em: https://www.scielo.br/pdf/cr/v44n6/a16514cr2013-1164.pdf. Acesso em: 02 ago. 2020.

MATSUNAGA, M.; BEMELMANS, P. F.; TOLEDO, P. E. N.; DULLEY, R. D.; OKAWA, H.; PEDROSO, I. A. Metodologia de custo de produção utilizada pelo IEA. Agricultura em São Paulo, n. 01, v. 23, p. 123-139, 1976. Disponível em: http://www.iea.sp.gov.br/ftpiea/rea/tomo1_76/artigo3. pdf. Acesso em: 04 jul. 2020.

OLIVEIRA, A. S. de; CUNHA, D. N. F. V. da; CAMPOS, J. M. S.; VALE, S. M. L. R. do; ASSIS, A. J. de. Identificação e quantificação de indicadores-referência de sistemas deprodução de leite.

Revista Brasileira de Zootecnia, n. 2, v. 36, p. 507-516, 2007. Disponível em: https://www.scielo. br/pdf/rbz/v36n2/30.pdf. Acesso em: 24 jul. 2020.

RADAVELLI, W. M. Caracterização do sistema compost barnem regiões subtropicais brasileiras. 2018. 89 f. Dissertação (Mestrado em Zootecnia) - Udesc Câmpus Chapecó, Chapecó, SC, 2018.

REIS, R. P.; MEDEIROS, A. L.; MONTEIRO, L. A. Custos de produção da atividade leiteira na região sul de Minas Gerais. Organizações Rurais e Agroindustriais, n. 2, v. 3, 2001. Disponível em: http://repositorio.ufla.br/handle/1/8952. Acesso em: 26 jul. 2020.

RENNÓ, F. P.; PEREIRA, J. C.; LEITE, C. A. M.; RODRIGUES, M. T.; CAMPOS, O. F. de; FONSECA, D. M. da; RENNÓ, L. N. Eficiência bioeconômica de estratégias de alimentação em sistemas de produção de leite: produção por animal e por área. Revista Brasileira de Zootecnia, n. 04, v. 37, p. 743-753, 2008. Disponível em: http://www.scielo.br/scielo.php?script=sci_ abstract\&pid=S1516-35982008000400022\&lng=pt\&nrm=iso\&tlng=pt. Acesso em: 08 dez. 2019.

SANTOS, G. dos; LOPES, M. A. Indicadores econômicos de sistemas de produção de leite em confinamento total com alto volume de produção diária. Ciência Animal Brasileira, n. 3, v. 15, p. 239-248, 2014. Disponível em: https://www.scielo.br/scielo.php?script=sci_arttext\&pid=S1809$68912014000300001 \& \operatorname{lng}=$ pt\&nrm=iso. Acesso em: 23 jul. 2020.

TELLES, P. G.; PACHECO, M. T. M.; PANOSSO, O.; PEGORINI, M. A. Análise de custos e viabilidade financeira na produção de leite in natura: estudo de caso em uma propriedade rural de Lagoa Vermelha - RS. XXVI Congresso Brasileiro de Custos, Florianópolis, 2017. Disponível em: https://anaiscbc.emnuvens.com.br/anais/article/view/4339. Acesso em: 25 jul. 2020.

VIANA, J. G. A.; ZEN, B.; KARLEC, F. SOUZA, R. S. de. Comportamento dos preços históricos do leite no Rio Grande do Sul, Brasil. Ciência e Agrotecnologia, n. 02, v. 34, p. 451-460, 2010. Disponível em: http://www.scielo.br/scielo.php?pid=S1413-70542010000200026\&script=sci abstract\&tlng=pt. Acesso em: 07 dez. 2019. 